\title{
Diagnosis and Treatment of Ulcerative Colitis with Cytomegalovirus Infection: Importance of Controlling Mucosal Inflammation to Prevent Cytomegalovirus Reactivation
}

\author{
Hiroshi Nakase, Yusuke Honzawa, Takahiko Toyonaga, Satoshi Yamada, Naoki Minami, Takuya Yoshino, \\ Minoru Matsuura \\ Department of Gastroenterology and Hepatology, Graduate School of Medicine, Kyoto University, Kyoto, Japan
}

\begin{abstract}
Human cytomegalovirus (HCMV) is a member of the herpesvirus family. HCMV infection persists throughout the host lifespan in a latent state following primary infection. The ability of HCMV to escape control by the host immune system and its resulting reactivation suggests the importance of ongoing immune surveillance in the prevention of HCMV reactivation. HCMV is a common cause of opportunistic infection that causes severe and fatal disease in immune-compromised individuals. In inflammatory bowel disease patients, particularly those with ulcerative colitis (UC), HCMV is often reactivated because these patients are frequently treated with immunosuppressive agents. This reactivation exacerbates colitis. Additionally, HCMV infection can induce severe colitis, even in patients with UC who have never been treated with immunosuppressive agents. However, the role of HCMV in colonic inflammation in patients with UC remains unclear. Here, we present previous and current clinical data on the diagnosis and treatment of HCMV infection in UC. Additionally, our experimental data from a newly established mouse model mimicking UC with concomitant CMV infection clearly demonstrate that inflammation could result in the exacerbation of UC disease activity with induction of HCMV reactivation. In summary, optimal control of colonic inflammation should be achieved in UC patients who are refractory to conventional immunosuppressive therapies and are positive for HCMV. (Intest Res 2014;12:5-11)
\end{abstract}

Key Words: Cytomegalovirus; Ulcerative colitis; Tumor necrosis factor alpha

\section{INTRODUCTION}

Corticosteroids and immunosuppressive agents have been used to treat patients with refractory UC. Much attention has been paid to the involvement of human cytomegalovirus

Received December 23, 2013. Revised December 27, 2013.

Accepted December 27, 2013.

Correspondence to Hiroshi Nakase, Department of Gastroenterology and

Hepatology, Graduate School of Medicine, Kyoto University, 54 Shogoin

Kawahara-cho, Sakyo-ku, Kyoto 606-8507, Japan. Tel: +81-75-751-4319,

Fax:+81-75-751-4303, E-mail: hiropy_n@kuhp.kyoto-u.ac.jp

Financial support: This work was supported by a Grant-in-aid for Scientific Research (C) from the Ministry of Culture and Science of Japan (grant 21590810) and a Health and Labor Sciences Research Grant for Research on Intractable Diseases, Japan. Conflict of interest: None.
(HCMV) infection in resistance to medical treatment for UC. ${ }^{1-3}$ Many studies have reported the prevalence of HCMV infection in patients with IBD. The prevalence of CMV infection in UC patients with severe colitis and steroid-refractory colitis has been reported as $21-38 \%^{4-8}$ and $32-36 \%,{ }^{7,9,10}$ respectively. The HCMV infection rates in patients with severe UC and patients with steroid-dependent UC are higher than those in patients with active Crohn's disease. ${ }^{11,12}$ HCMV infection causes significant clinical morbidity in patients with UC. In this regard, the establishment of an appropriate diagnosis and treatment for HCMV infection in UC is a critical issue for gastroenterologists. This article highlights diagnostic and therapeutic strategies for HCMV infection in UC, and provides new insights into the mechanism of HCMV reactivation.

๑ Copyright 2014. Korean Association for the Study of Intestinal Diseases. All rights reserved.

This is an Open Access article distributed under the terms of the Creative Commons Attribution Non-Commercial License (http://creativecommons.org/licenses/by-nc/3.0)

which permits unrestricted non-commercial use, distribution, and reproduction in any medium, provided the original work is properly cited. 


\section{HUMAN CYTOMEGALOVIRUS}

HCMV is a $\beta$-herpesvirus and has a $235 \mathrm{kbp}$ genome. ${ }^{13-15}$ HCMV is a host species-specific pathogen that causes lifelong persistent infections. Under conditions of reduced immune responses, HCMV can cause acute systemic infections with replication in virtually any organ. Fibroblasts, epithelial cells, smooth muscle cells, macrophages, and endothelial cells were found to be the predominant targets of HCMV infection in the lung, gastrointestinal, and placental tissues. ${ }^{16-18}$

The myeloid lineage is an important site in vivo for the persistence of latent HCMV genomes. The strong link between the reactivation of latent virus and the differentiation state of cells in the myeloid lineage appears to be important in HCMV biology. The ex vivo differentiation of CD34-positive or CD14-positive cells to the specific lineage of myeloid dendritic cells (DCs) results in the reactivation of HCMV gene expression. ${ }^{19-21}$

Several reports have suggested that macrophages and, subsequently, DCs, are fully permissive for infection, but monocytes are not. In addition, it was reported that proinflammatory cytokines including tumor necrosis factor (TNF)- $\alpha$ and granulocyte macrophage-colony stimulating factor could induce HCMV-harboring monocytes to differentiate into macrophages. ${ }^{22-24}$ These data strongly suggest that HCMVharboring macrophages and DCs migrate into inflamed tissue to further propagate HCMV infection. However, the mechanisms underlying the maintenance of the latent state and reactivation of the latent virus remain unclear.

\section{HCMV DIAGNOSTIC APPROACH}

\section{Isolation Culture}

This is a direct culture system with human fetal lung fibroblasts to confirm HCMV infection. The problem with this procedure is that the cytopathic effect typically evolves very slowly; it can take up to 21 days to visualize the cytopathic effect of HCMV infection in culture cells. Additionally, this technique lacks sensitivity. ${ }^{25,26}$

\section{Serology}

HCMV infection is a common viral infection in humans and $60-70 \%$ of adults are carriers of HCMV (this percentage may slightly decrease in the near future). HCMV infection is diagnosed by comparing the antibody titer at the acute stage with that at the recovery stage. HCMV-specific IgM levels will increase 2-6 weeks after primary infection. The titer of IgM antibodies usually decreases in 2-3 months in healthy people and rarely reappears during HCMV reactivation (the frequency is $0.1-2 \%$ ). At least a four-fold increase of HCMVspecific IgG antibody is considered to be a criterion for diagnosis of HCMV-specific infection and, therefore, paired serum samples obtained at least 2-4 weeks apart are needed. ${ }^{27-29}$ Generally, in the case of HCMV reactivation, the titer for HCMV-specific IgG does not change. Thus, the measurement of HCMVs-specific antibodies is of limited value in the evaluation of HCMV reactivation from carriers, whereas it is useful to evaluate CMV infection in HCMV-naive patients.

\section{HCMV Antigenemia}

This method is used to directly detect the antigen of HCMV in specimen materials without separating HCMV from tissues. The infected cells are detected by immunofluorescence using antibodies against the immediate-early antigen and the HCMV pp65 antigen of HCMV. ${ }^{29}$ This method can be used for not only the peripheral blood but also the cerebrospinal fluid. The HCMV antigenemia method has a sensitivity of $60-100 \%$ and a specificity of $83-100 \%{ }^{30,31}$ In general, the detection of antigen (pp65)-positive cells in peripheral blood cells reflects active reactivation of HCMV; however, it should be remembered that the positive finding of HCMV antigenemia does not necessarily reflect HCMV infection in gastrointestinal organs.

\section{Histopathological Diagnosis of HCMV}

The golden standard for diagnosing HCMV infection in each organ is to ascertain the presence of cytomegalic cells by histology (typical HCMV infected cells become huge and contain cytomegalic inclusion bodies with a halo). ${ }^{32-35}$ HCMV infection not only generates inclusion bodies in the nucleus but also produces similar inclusion bodies in the cytoplasm (cytoplasmic inclusion bodies). The sensitivity of HCMV detection in tissue specimens has been improved by immunoperoxidase or immunofluorescence staining for HCMV antigens using monoclonal antibodies and/or in situ DNA hybridization. However, there have been no reports regarding how many biopsy specimens are required to prove absence of cytomegalic cells.

\section{Diagnosis of HCMV by Polymerase Chain Reaction (PCR) Analysis}

PCR has been used to identify HCMV-DNA in urine, blood, and tissues. Several studies have used the quantitative realtime PCR assay to detect the immediate-early gene for rapid quantification of HCMV-DNA in clinical samples. ${ }^{36-39}$ PCR analysis is more useful for diagnosing HCMV infection and monitoring the viral load than HCMV antigenemia. In fact, our group demonstrated the usefulness of the mucosal PCR method (using biopsy specimens) for diagnosing HCMV infection in active UC. ${ }^{40}$ However, the high sensitivity of the quantitative real-time PCR assay may result in low specificity for diagnosing active HCMV infection because HCMV-DNA in samples with low copy number, would be detected by the 
PCR assay but may not actually reflect active infection in the organs; rather, it may indicate "innocent bystander reactivation".

\section{INVOLVEMENT OF CMV REACTIVATION IN THE PATHOPHYSIOLOGY OF UC}

HCMV infection is considered an important exacerbating factor in UC patients. The first case with an association between UC and HCMV infection was described by Powell et al. in $1961{ }^{42}$ Since then, numerous cases reports and many studies have suggested the association of HCMV infection with the flare-up of UC., ${ }^{3,10,43,44}$ Retrospective studies have reported the presence of HCMV in surgical specimens of UC patients who underwent colectomy because of toxic megacolon or steroid resistance. ${ }^{3}$ Additionally, it is well-known that the steroid-refractory condition in UC is strongly associated with HCMV infection. A case-control study showed that the ratio of positive HCMV findings by immunohistochemistry (IHC) in surgical specimens of steroid-refractory UC patients and non-refractory UC was $25 \%$ and $2.5 \%$, respectively. ${ }^{7}$ In our facility, $56.7 \%$ of UC patients who were refractory to immunosuppressive therapies were diagnosed with HCMV infection by the mucosal PCR method.$^{40}$ In contrast, Fukuchi et al. reported that $29.4 \%$ of active UC patients who did not receive any immunosuppressive therapies such as corticosteroids were positive for HCMV-DNA in their colonic mucosa. ${ }^{45}$ These findings are similar to those of Roblin and Demènech reports. These data suggest that preceding mucosal inflammation in UC is important for inducing HCMV reactivation in intestinal tissue. Interestingly, Hommes et al. reported that HCMV in intestinal tissue biopsies was approximately 20 times more likely in UC patients than in controls with non-inflammatory disease ${ }^{46}$ From the clinical aspect, we speculate that disease activity together with the use of immunosuppressive drugs may predispose UC patients to colonic reactivation of HCMV.

\section{DIAGNOSIS OF HCMV INFECTION IN UC}

Detection of HCMV antigen (pp65 antigenemia assay) and HCMV-DNA (PCR) in the peripheral blood, which can quantify viral load and can be generally applied for diagnosis of HCMV infection, are not necessarily useful for diagnosing HCMV colitis because gastrointestinal disease related to HCMV infection can occur even when HCMV is not detected in the blood. ${ }^{5}$ Gastroenterologists typically agree that endoscopic examination is required for evaluating HCMV infection in patients with UC flare-ups. However, previous reports suggested that there were no characteristic endoscopic findings of UC flare-ups accompanied with HCMV infection. ${ }^{40,47-49}$ In this regard, histological evaluation of biopsy specimens is essential to examine HCMV infection in colonic mucosa of active UC. Generally, the detection of HCMV in biopsy specimens by histologic examinations, such as the detection of inclusion bodies and IHC, is the golden standard for determining the involvement of HCMV in gastrointestinal diseases. However, it is important to remember that histological markers of HCMV disease in colonic tissue are negative even when the HCMV-DNA load is high at the tissue level. Yoshino et al. reported the usefulness of the mucosal PCR method for detecting HCMV infection in UC patients. ${ }^{40}$ Roblin et al. reported the importance of determining HCMV-DNA load by PCR because this quantitative detection of HCMV-DNA in intestinal tissue could predict resistance to steroid treatment in UC patients. ${ }^{50}$ In addition, the European Crohn's and Colitis Organization guidelines recommend the use of tissue PCR as an alternative to IHC for investigation of $\mathrm{CMV}$ infection in immunomodulation-refractory cases of IBD. ${ }^{51}$ In this regard, the application of the mucosal PCR method for evaluating CMV infection should be considered in HCMV infectionsuspected cases negative for IHC findings.

\section{HOW DO WE TREAT ACTIVE UC WITH CONCOMITANT HCMV INFECTION?}

Several reports have indicated the effect of antiviral treatments in UC patients with CMV infection refractory to corticosteroid therapy. However, in the current clinical setting, we consider that all UC patients in whom HCMV is detected do not require antiviral therapies. In fact, we have not yet established an exact method to identify patients whose disease improves with antiviral therapy. Therefore, there is no standardized therapeutic regimen for UC patients with concomitant HCMV infection.

When we treat UC patients with concomitant HCMV infection, we consider the selection of anti-inflammatory therapies that do not result in HCMV reactivation. Granulocyte and monocyte adsorptive apheresis (GMAA) with the adacolumn (JIMRO, Gunma, Japan) is natural biological therapy for UC that selectively removes granulocytes/macrophages that produce inflammatory cytokines, without removing lymphocytes. Several reports have demonstrated that GMAA could be a suitable therapeutic option for patients with active UC prior to starting corticosteroid treatment. ${ }^{52}$ Yoshino et al. reported that GMAA did not affect HCMV reactivation in UC patients with a history of HCMV infection. ${ }^{53}$ Fukuchi et al. reported the effect of GMAA on steroid-naïve active UC patients with concomitant HCMV infection. ${ }^{45}$ Their data demonstrated that the clinical remission ratio of GMAA in UC patients positive for HCMV was 73.3\%. Interestingly, this study showed that HCMV-DNA in colonic mucosa became negative in all UC patients positive for CMV who achieved clinical remission after GMAA. Thus, these clinical data indicate the important issue that local intestinal inflammation can trigger HCMV reactivation in a subpopulation of UC patients. Thus, GMAA may be a promising option for active UC with concomitant HCMV infection (Fig. 1). 


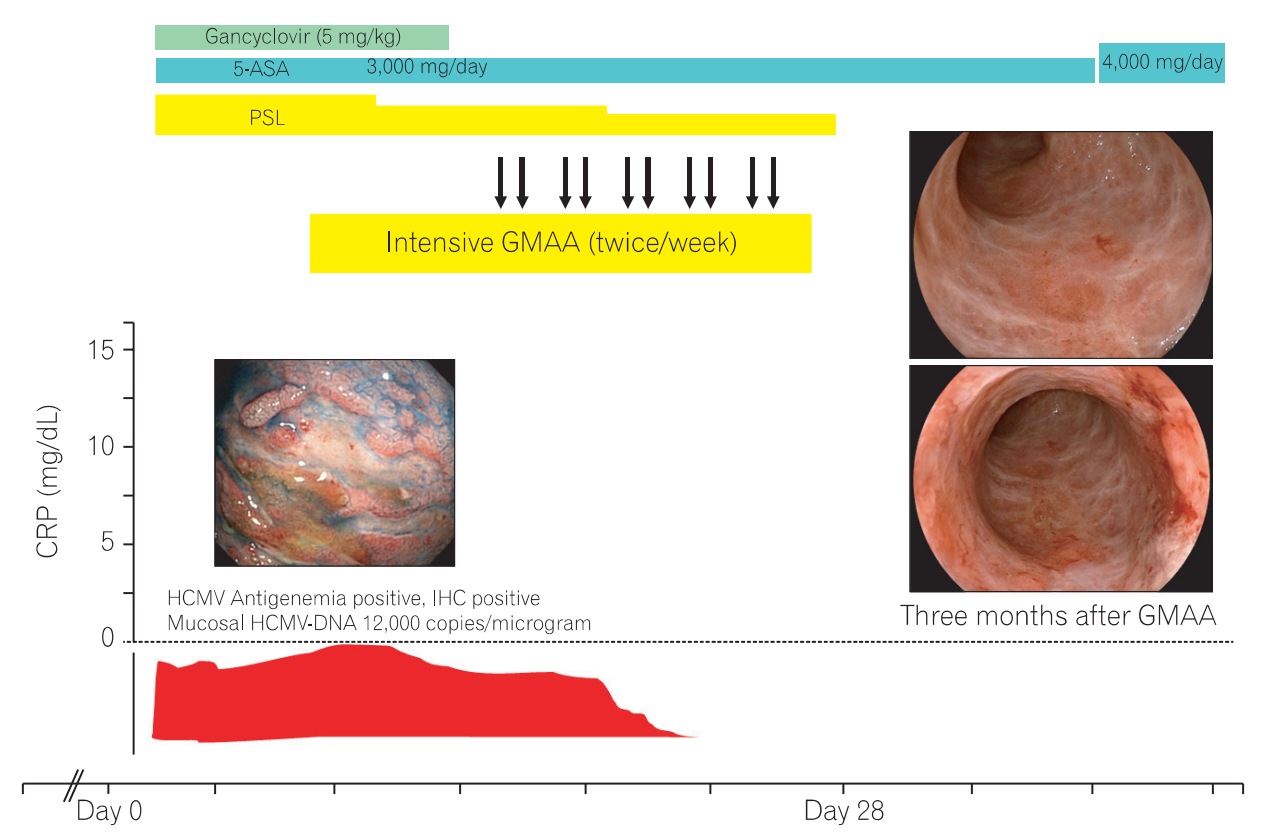

Fig. 1. Effect of granulocyte and monocyte adsorptive apheresis (GMAA) on UC patient with concomitant human cytomegalovirus (HCMV) infection. Cases of steroid-resistant UC patients with concomitant HCMV infection who were successfully treated with GMAA. Forty-nine female patients with UC, who were refractory to $60 \mathrm{mg}$ of prednisolone (PSL), were transferred to our hospital. HCMV antigenemia, immunohistochemistry (IHC), and HCMV-DNA in the colonic mucosa were observed. After starting gancyclovir (5 mg/kg), abdominal symptoms such as hematochezia and abdominal pain did not subside. We initiated intensive GMAA (twice/week). After 10 applications of GMAA, the abdominal symptoms disappeared and PSL could be completely tapered. Sigmoidoscopy 3 months after initiation of GMAA showed the disappearance of the ulcerative lesions and scar formation. 5-ASA, 5-aminosalicylic acid.

Kim et al. reported data regarding the importance of controlling intestinal inflammation of UC to avoid HCMV infection. ${ }^{54}$ They performed a prospective, multicenter study in which 72 patients with moderate to severe UC were treated with intravenous steroids. Among the enrolled patients, 17 UC patients with concomitant HCMV infections improved with steroid therapy alone and did not require antiviral therapies. In contrast, 14 UC patients with concomitant HCMV infection who did not respond to steroid therapy required ganciclovir treatment. Kim et al.s data also suggested that insufficient control of local inflammation could lead to HCMV infection and complicate the condition of UC flare-ups.

Roblin et al. showed striking data that UC patients with a HCMV-DNA load higher than 250 copies/mg in tissue required early antiviral treatment. ${ }^{50}$ Their data showed the importance of evaluating HCMV-DNA load in the colonic tissue of UC patients for identifying UC patients positive for HCMV-DNA in colonic tissue who should be treated with antiviral treatment. Their data also suggested that a high level of HCMV-DNA in the colonic mucosa could affect the efficacy of immunomodulatory treatments, and antiviral treatment should be implemented to prevent further HCMV reactivation during the use of immunosuppressive treatments for patients who exhibit a high load of HCMV-DNA. However, whether a HCMV-DNA copy number higher than 250 copies/ mg in tissue is optimal for starting antiviral therapy in refractory cases should be elucidated in the future.

Considering that TNF- $\alpha$ plays an important role in HCMV reactivation in both monocytes and DCs, anti-TNF- $\alpha$ therapy may be useful in UC patients with concomitant HCMV infection. D' Ovidio et al. evaluated the presence and severity of HCMV infection and disease in infliximab-treated IBD patient $^{55}$ and concluded that active HCMV infection did not progress to disease following infliximab therapy, and that the response to infliximab therapy did not appear to be influenced by HCMV infection/disease. Pillet et al. proposed an algorithm for management of HCMV infection in IBD. ${ }^{56}$ They recommended the use of anti-TNF- $\alpha$ therapy in UC patients with concomitant HCMV infection. More studies are necessary to assess this issue in the future.

Whether or not UC patients exhibit CMV-DNA in inflamed mucosa may depend on both the patient's immune condition and the following immunosuppressive therapy. Additionally, how and when to start antiviral treatment for UC patients with concomitant CMV infection remains unclear. In this regard, the best way to treat refractory UC patients with concomitant CMV infection may at least be to reduce colonic inflammation without affecting HCMV infection using such methods such as GMAA and anti-TNF- $\alpha$ therapy. 


\section{ESTABLISHMENT OF A CMV-INFECTED IBD MOUSE MODEL: FURTHER UNDERSTANDING OF MECHANISM AND INVOLVEMENT OF HCMV INFECTION IN UC}

In clinical practice, numerous case series have been reported on HCMV detection in patients with severe IBD unresponsive to standard immunosuppressive therapy.

Moreover, it is well known that the prognosis of IBD patients complicated by HCMV infection is poor. Therefore, sufficient understanding of the effects of HCMV on IBD is important to manage these patients. HCMV reactivation is thought to be mainly triggered by TNF- $\alpha$. However, the mechanism by which CMV aggravates IBD remains unclear.

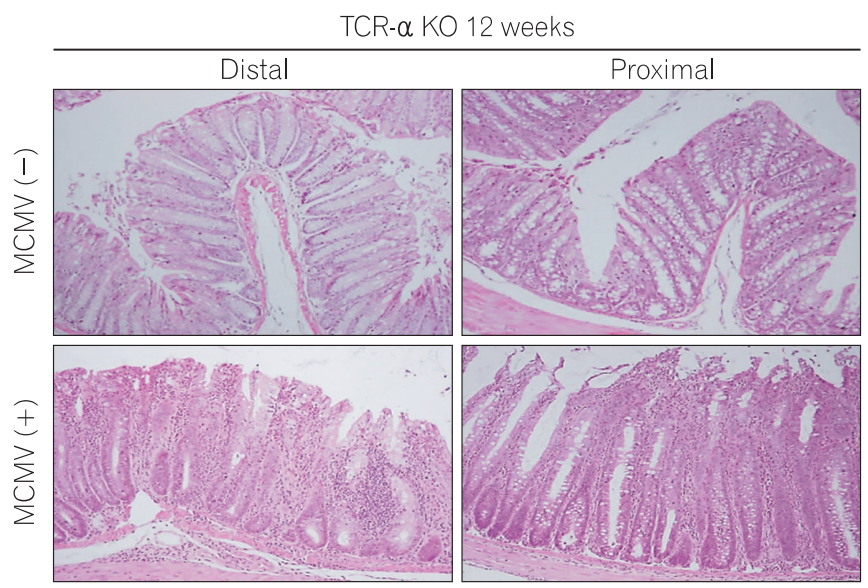

Fig. 2. Histologic findings in the proximal and distal colon in T cell receptor (TCR)- $\alpha$ knockout (KO) mice with and without mouse cytomegalovirus (MCMV) infection at 12 weeks. In comparison with uninfected KO mice, histological examination revealed severe hyperplasia of the epithelial cells, infiltration of inflammatory cells, and crypt loss in infected TCR- $\alpha$ KO mice at 12 weeks $(H \& E, \times 200)$.
Recently, we reported for the first time an experimental IBD mouse model exacerbated by CMV infection. ${ }^{57}$ Generally, mouse cytomegalovirus (MCMV) shares a high sequence homology with HCMV and serves as a useful tool to understand HCMV pathogenesis. The T cell receptor (TCR)- $\alpha$ Knockout (KO) mouse develops spontaneous bowel inflammation, which is similar to UC. First, we established MCMV-latent infected TCR- $\alpha$ KO mice mimicking HCMV latent infection in UC patients. In this study, IHC findings demonstrated an increase in MCMV-infected cells as colitis developed in TCR- $\alpha$ KO mice. It should be noted that MCMV infected cells were detected predominantly in inflamed colonic mucosa. This result was compatible with clinical data showing that HCMV was not present in non-inflamed but present in inflamed colonic mucosa among patients with severe UC. Additionally, MCMV-infected TCR- $\alpha$ KO mice developed more severe colitis than not-infected mice (Fig. 2). HCMV is reported to induce migration of neutrophils and reprogram monocyte differentiation toward M1 macrophages in vitro ${ }^{58}$ In fact, we found more migrating neutrophils and M1 macrophages at the inflammatory site in the colon of this murine model. Immunohistochemical study with this murine model demonstrated that MCMV latently infected perivascular stromal cells, including pericytes. These data suggest that HCMV infection in the colonic mucosa of UC patients could spread from perivascular stromal cells to endothelial cells and epithelial cells with the progression of colitis. We consider that the application of this model will aid in investigating the more detailed mechanism of aggravation in IBD with HCMV infection and treatment of these patients.

\section{CONCLUSIONS}

Many studies have been performed to elucidate the relationship between HCMV infection and UC flare-ups. Current clinical data and the experimental data obtained from our

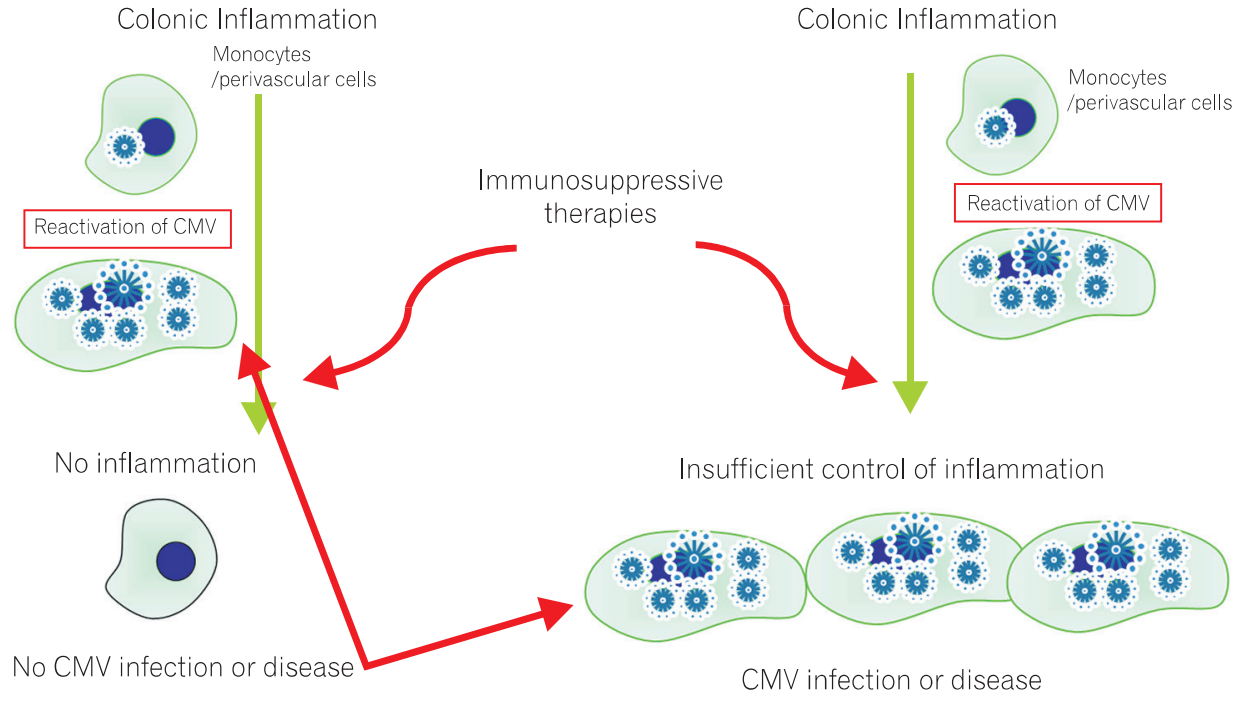

Fig. 3. Proposed mechanisms of human cytomegalovirus (HCMV) reactivation in UC. Tissue PCR is useful and accurate modality for diagnosis of CMV infection in patients with UC. 
newly established mouse model demonstrate that insufficient control of inflammation could result in exacerbation of UC disease activity with HCMV reactivation (Fig. 3). In this regard, we consider that optimal control of colonic inflammation should be achieved in UC patients who are refractory to conventional immunosuppressive therapies and are positive for HCMV. Further, the timing of the initiation of antiviral therapy is critical for therapeutic strategies in active UC patients who are positive for HCMV. Investigation of the HCMVDNA copy number in colonic mucosa by mucosal PCR may hold the key to solving this issue.

\section{REFERENCES}

1. Nakase H, Matsumura K, Yoshino T, Chiba T. Systematic review: cytomegalovirus infection in inflammatory bowel disease. J Gastroenterol 2008;43:735-740.

2. Loftus EV, Jr., Alexander GL, Carpenter HA. Cytomegalovirus as an exacerbating factor in ulcerative colitis. J Clin Gastroenterol 1994;19:306-309.

3. Cooper HS, Raffensperger EC, Jonas L, Fitts WT, Jr. Cytomegalovirus inclusions in patients with ulcerative colitis and toxic dilation requiring colonic resection. Gastroenterology 1977;72:12531256.

4. Osaki R, Andoh A, Tsujikawa T, et al. Acute cytomegalovirus infection superimposed on corticosteroid-naive ulcerative colitis. Intern Med 2008;47:1341-1344.

5. Matsuoka K, Iwao Y, Mori T, et al. Cytomegalovirus is frequently reactivated and disappears without antiviral agents in ulcerative colitis patients. Am J Gastroenterol 2007;102:331-337.

6. Dimitroulia E, Spanakis N, Konstantinidou AE, Legakis NJ, Tsakris A. Frequent detection of cytomegalovirus in the intestine of patients with inflammatory bowel disease. Inflamm Bowel Dis 2006;12:879-884.

7. Criscuoli V, Casa A, Orlando A, et al. Severe acute colitis associated with CMV: a prevalence study. Dig Liver Dis 2004;36:818-820.

8. Wada Y, Matsui T, Matake H, et al. Intractable ulcerative colitis caused by cytomegalovirus infection: a prospective study on prevalence, diagnosis, and treatment. Dis Colon Rectum 2003;46(Suppl 10):S59-S65.

9. Domenech E, Vega R, Ojanguren I, et al. Cytomegalovirus infection in ulcerative colitis: a prospective, comparative study on prevalence and diagnostic strategy. Inflamm Bowel Dis 2008;14:1373-1379.

10. Cottone M, Pietrosi G, Martorana G, et al. Prevalence of cytomegalovirus infection in severe refractory ulcerative and Crohn's colitis. Am J Gastroenterol 2001;96:773-775.

11. Kim JJ, Simpson N, Klipfel N, Debose R, Barr N, Laine L. Cytomegalovirus infection in patients with active inflammatory bowel disease. Dig Dis Sci 2010;55:1059-1065.

12. Nakase H, Yoshino T, Honzawa Y, Chiba T. Low prevalence of CMV infection in patients with Crohn's disease in comparison with ulcerative colitis: effect of different immune response on prevalence of CMV infection. Dig Dis Sci 2010;55:1498-1499.
13. McGavran MH, Smith MG. Ultrastructural, cytochemical, and microchemical observations on cytomegalovirus (salivary gland virus) infection of human cells in tissue culture. Exp Mol Pathol 1965;76:1-10.

14. Chen DH, Jiang H, Lee M, Liu F, Zhou ZH. Three-dimensional visualization of tegument/capsid interactions in the intact human cytomegalovirus. Virology 1999;260:10-16.

15. Pass RF. Epidemiology and transmission of cytomegalovirus. J Infect Dis 1985;152:243-248.

16. Roberts WH, Sneddon JM, Waldman J, Stephens RE. Cytomegalovirus infection of gastrointestinal endothelium demonstrated by simultaneous nucleic acid hybridization and immunohistochemistry. Arch Pathol Lab Med 1989;113:461-464.

17. Muhlemann K, Miller RK, Metlay L, Menegus MA. Cytomegalovirus infection of the human placenta: an immunocytochemical study. Hum Pathol 1992;23:1234-1237.

18. Sinzger C, Muntefering H, Loning T, Stoss H, Plachter B, Jahn G. Cell types infected in human cytomegalovirus placentitis identified by immunohistochemical double staining. Virchows Arch A Pathol Anat Histopathol 1993;423:249-256.

19. Reeves MB, MacAry PA, Lehner PJ, Sissons JG, Sinclair JH. Latency, chromatin remodeling, and reactivation of human cytomegalovirus in the dendritic cells of healthy carriers. Proc Natl Acad Sci U S A 2005;102:4140-4145.

20. Sallusto F, Lanzavecchia A. Efficient presentation of soluble antigen by cultured human dendritic cells is maintained by granulocyte/macrophage colony-stimulating factor plus interleukin 4 and downregulated by tumor necrosis factor alpha. J Exp Med 1994;179:1109-1118.

21. Strobl H, Bello-Fernandez C, Riedl E, et al. flt3 ligand in cooperation with transforming growth factor-betal potentiates in vitro development of Langerhans-type dendritic cells and allows single-cell dendritic cell cluster formation under serum-free conditions. Blood 1997;90:1425-1434.

22. Hertel L, Lacaille VG, Strobl H, Mellins ED, Mocarski ES. Susceptibility of immature and mature Langerhans cell-type dendritic cells to infection and immunomodulation by human cytomegalovirus. J Virol 2003;77:7563-7574.

23. Lathey JL, Spector SA. Unrestricted replication of human cytomegalovirus in hydrocortisone-treated macrophages. J Virol 1991;65:6371-6375.

24. Riegler S, Hebart H, Einsele H, Brossart P, Jahn G, Sinzger C. Monocyte-derived dendritic cells are permissive to the complete replicative cycle of human cytomegalovirus. J Gen Virol 2000;81:393-399.

25. Rothbarth PH, Diepersloot RJ, Metselaar HJ, Nooyen Y, Velzing J, Weimar W. Rapid demonstration of cytomegalovirus in clinical specimens. Infection 1987;15:228-231.

26. de la Hoz RE, Stephens G, Sherlock C. Diagnosis and treatment approaches of CMV infections in adult patients. J Clin Virol 2002;25(Suppl 2):S1-S12.

27. Revello MG, Zavattoni M, Furione M, Lilleri D, Gorini G, Gerna G. Diagnosis and outcome of preconceptional and periconceptional primary human cytomegalovirus infections. J Infect Dis 
2002;186:553-557.

28. Revello MG, Gerna G. Diagnosis and management of human cytomegalovirus infection in the mother, fetus, and newborn infant. Clin Microbiol Rev 2002;15:680-715.

29. Rowshani AT, Bemelman FJ, van Leeuwen EM, van Lier RA, ten Berge IJ. Clinical and immunologic aspects of cytomegalovirus infection in solid organ transplant recipients. Transplantation 2005;79:381-386.

30. Lazzarotto T, Dal Monte P, Landini MP. Recent advances in the diagnosis of cytomegalovirus infection. Ann Biol Clin (Paris) 1996;54:259-265.

31. Ljungman P, Griffiths P, Paya C. Definitions of cytomegalovirus infection and disease in transplant recipients. Clin Infect Dis 2002;34:1094-1097.

32. Hinnant KL, Rotterdam HZ, Bell ET, Tapper ML. Cytomegalovirus infection of the alimentary tract: a clinicopathological correlation. Am J Gastroenterol 1986;81:944-950.

33. Culpepper-Morgan JA, Kotler DP, Scholes JV, Tierney AR. Evaluation of diagnostic criteria for mucosal cytomegalic inclusion disease in the acquired immune deficiency syndrome. Am J Gastroenterol 1987;82:1264-1270.

34. Jacobson MA, Mills J. Serious cytomegalovirus disease in the acquired immunodeficiency syndrome (AIDS). Clinical findings, diagnosis, and treatment. Ann Intern Med 1988;108:585-594.

35. Wilcox CM, Diehl DL, Cello JP, Margaretten W, Jacobson MA. Cytomegalovirus esophagitis in patients with AIDS. A clinical, endoscopic, and pathologic correlation. Ann Intern Med 1990;113:589-593.

36. Rogers BB, Alpert LC, Hine EA, Buffone GJ. Analysis of DNA in fresh and fixed tissue by the polymerase chain reaction. Am J Pathol 1990;136:541-548.

37. Chang MH, Huang HH, Huang ES, Kao CL, Hsu HY, Lee CY. Polymerase chain reaction to detect human cytomegalovirus in livers of infants with neonatal hepatitis. Gastroenterology 1992;103:1022-1025.

38. Persons DL, Moore JA, Fishback JL. Comparison of polymerase chain reaction, DNA hybridization, and histology with viral culture to detect cytomegalovirus in immunosuppressed patients. Mod Pathol 1991;4:149-153.

39. Chen YT, Mercer GO, Cheigh JS, Mouradian JA. Cytomegalovirus infection of renal allografts. Detection by polymerase chain reaction. Transplantation 1992;53:99-102.

40. Yoshino T, Nakase H, Ueno S, et al. Usefulness of quantitative real-time PCR assay for early detection of cytomegalovirus infection in patients with ulcerative colitis refractory to immunosuppressive therapies. Inflamm Bowel Dis 2007;13:1516-1521.

41. Lawlor G, Moss AC. Cytomegalovirus in inflammatory bowel disease: pathogen or innocent bystander? Inflamm Bowel Dis 2010;16:1620-1627.

42. Powell RD, Warner NE, Levine RS, Kirsner JB. Cytomegalic inclusion disease and ulcerative colitis; report of a case in a young adult. Am J Med 1961;30:334-340.

43. Papadakis KA, Tung JK, Binder SW, et al. Outcome of cytomegalovirus infections in patients with inflammatory bowel disease.
Am J Gastroenterol 2001;96:2137-2142.

44. Eyre-Brook IA, Dundas S. Incidence and clinical significance of colonic cytomegalovirus infection in idiopathic inflammatory bowel disease requiring colectomy. Gut 1986;27:1419-1425.

45. Fukuchi T, Nakase H, Matsuura M, et al. Effect of intensive granulocyte and monocyte adsorptive apheresis in patients with ulcerative colitis positive for cytomegalovirus. J Crohns Colitis 2013;7:803-811.

46. Hommes DW, Sterringa G, van Deventer SJ, Tytgat GN, Weel J. The pathogenicity of cytomegalovirus in inflammatory bowel disease: a systematic review and evidence-based recommendations for future research. Inflamm Bowel Dis 2004;10:245-250.

47. Kandiel A, Lashner B. Cytomegalovirus colitis complicating inflammatory bowel disease. Am J Gastroenterol 2006;101:28572865.

48. Goodgame RW. Gastrointestinal cytomegalovirus disease. Ann Intern Med 1993;119:924-935.

49. Korkmaz M, Kunefeci G, Selcuk H, et al. The role of early colonoscopy in CMV colitis of transplant recipients. Transplant Proc 2005;37:3059-3060.

50. Roblin X, Pillet S, Oussalah A, et al. Cytomegalovirus load in inflamed intestinal tissue is predictive of resistance to immunosuppressive therapy in ulcerative colitis. Am J Gastroenterol 2011;106:2001-2008.

51. Rahier JF, Ben-Horin S, Chowers Y, et al. European evidencebased Consensus on the prevention, diagnosis and management of opportunistic infections in inflammatory bowel disease. J Crohns Colitis 2009;3:47-91.

52. Yoshino T, Nakase H, Minami N, et al. Efficacy and safety of granulocyte and monocyte adsorption apheresis for ulcerative colitis: A meta-analysis. Dig Liver Dis doi:10.1016/j.dld.2013.10.011. Published online ahead of print 21 November 2013.

53. Yoshino T, Nakase H, Matsuura M, et al. Effect and safety of granulocyte-monocyte adsorption apheresis for patients with ulcerative colitis positive for cytomegalovirus in comparison with immunosuppressants. Digestion 2011;84:3-9.

54. Kim YS, Kim YH, Kim JS, et al. The prevalence and efficacy of ganciclovir on steroid-refractory ulcerative colitis with cytomegalovirus infection: a prospective multicenter study. J Clin Gastroenterol 2012;46:51-56.

55. D'Ovidio V, Vernia P, Gentile G, et al. Cytomegalovirus infection in inflammatory bowel disease patients undergoing anti-TNFalpha therapy. J Clin Virol 2008;43:180-183.

56. Pillet S, Pozzetto B, Jarlot C, Paul S, Roblin X. Management of cytomegalovirus infection in inflammatory bowel diseases. Dig Liver Dis 2012;44:541-548.

57. Matsumura K, Nakase H, Kosugi I, et al. Establishment of a novel mouse model of ulcerative colitis with concomitant cytomegalovirus infection: in vivo identification of cytomegalovirus persistent infected cells. Inflamm Bowel Dis 2013;19:1951-1963.

58. Chan G, Bivins-Smith ER, Smith MS, Smith PM, Yurochko AD. Transcriptome analysis reveals human cytomegalovirus reprograms monocyte differentiation toward an M1 macrophage. J Immunol 2008;181:698-711. 